\title{
Segurança do paciente no intraoperatório do transplante hepático: revisão integrativa
}

Intraoperative patient safety during liver transplantation: integrative review Seguridad del paciente en el intraoperatorio del trasplante de hígado: revisión integradora

Schirley de Espindola id https://orcid.org/0000-0001-8593-62271

Keyla Cristine do Nascimento iD https://orcid.org/0000-0003-4157-28091

Neide da Silva Knihs io hitps://orcid.org/0000-0003-0639-28291

Ana Graziela Alvarez io https://orcid.org/0000-0002-3943-9884

Luciara Fabiane Sebold io https://orcid.org/0000-0002-5023-90581

Sibele Maria Schuantes Paim io https://orcid.org/0000-0003-4249-9148'

Como citar:

Espindola S, Nascimento KC, Knihs NS, Alvarez LF, Sebold LF, Paim SM. Segurança do paciente no intraoperatório do transplante hepático: revisão integrativa. Acta Paul Enferm. 2020;33:e-APE20180187

DOI

http://dx.doi.org/10.37689/ acta-ape/2020AR0187

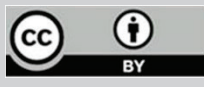
rio: Transplante de fígado; Segurança do paciente; Lista de checagem

Keywords Intraoperative period; liver transplantation; Patien safety; Checklist

Descriptores

Periodo intraoperatorio; Trasplante de hígado; Seguridad del paciente; Lista de verificación

Submetido 30 de Agosto de 2018

Aceito 4 de Setembro de 2019

Autor correspondente Neide da Silva Knihs. E-mail: neide.knihs@ufsc.br

\section{Resumo}

Objetivo: Analisar evidências cientificas que subsidiem práticas seguras no intraoperatório do transplante hepático. Métodos: Revisão integrativa da literatura, a partir de seis bases de dados. A revisão seguiu seis etapas: elaboração da questão de pesquisa; definição dos critérios para a busca na literatura; coleta dos dados; análise crítica do material obtido; avaliação e interpretação criteriosa das informaç̧ões; e apresentação dos resultados obtidos.

Resultados: Foram identificadas 511 publicações, sendo 16 incluídas para análise, considerando-se os critérios de inclusão e exclusão. As evidências que subsidiam as práticas seguras em transplante hepático foram apresentadas nas seguintes categorias: Cuidados relacionados à hipotermia, Recomendações para extubação precoce, Transfusão de hemocomponentes e Protocolo anestésico.

Conclusão: As evidências apontadas na revisão integrativa apresentam subsídios para a elaboração de um checklist de cirurgia segura direcionado ao transplante hepático.

\section{Abstract}

Objective: To analyze the scientific evidence that supports safe intraoperative liver transplantation practices.

Methods: Integrative literature review within six databases. The review followed six steps: development of the research question; definition of criteria for searching the literature; data collection; critical analysis of the material obtained; evaluation and interpretation of information; and, presentation of the results obtained.

Results: A total of 511 publications were identified, 16 of which were included for analysis, considering the inclusion and exclusion criteria. Evidence supporting safe liver transplantation practices was presented in the following categories: Hypothermia-related care, Recommendations for early extubation, Blood component transfusion, and, Anesthesia protocol.

Conclusion: The evidence found in the integrative review provides support for development of a safe surgery checklist related to liver transplantation.

\section{Resumen}

Objetivo: Analizar las evidencias cientificas que proporcionan prácticas seguras en el intraoperatorio del trasplante de hígado.

Métodos: Revisión integradora de la literatura a partir de seis bases de datos. La revisión se realizó en seis etapas: elaboración de la pregunta de investigación, definición de los criterios para la búsqueda de literatura, recolección de datos, análisis crítico del material obtenido, evaluación e interpretación criteriosa de la información y presentación de los resultados obtenidos. 
Resultados: Se identificaron 511 publicaciones, de las cuales 16 se incluyeron para el análisis, considerando los criterios de inclusión y exclusión. Las evidencias que proporcionan las prácticas seguras en el trasplante de hígado fueron presentadas en las siguientes categorías: Cuidados relacionados con la hipotermia, Recomendaciones para la extubación precoz, Transfusión de hemocomponentes y Protocolo anestésico.

Conclusión: Las evidencias señaladas en la revisión integradora presentan datos para la elaboración de un checklist de cirugía segura orientada al trasplante de hígado.

\section{Introdução}

Nos últimos anos observamos grandes avanços na área de saúde e na segurança do paciente. No cenário cirúrgico, destacam-se as iniciativas promovidas pela Organização Mundial da Saúde (OMS), especialmente o desafio global "Cirurgias Seguras Salvam Vidas" de 2009 e a publicação do guideline e checklist de cirurgia segura. ${ }^{(1,2)}$

No Brasil, em 2013, a Agência Nacional de Vigilância Sanitária (ANVISA) lançou o Programa Nacional de Segurança do Paciente, incluindo também uma sugestão de protocolo de segurança cirúrgica e checklist de cirurgia segura, fundamentais para a qualidade na assistência perioperatória. ${ }^{(1,2)}$

Os centros cirúrgicos são unidades complexas, com intensa circulação de profissionais e pacientes, onde ocorrem procedimentos de diferentes complexidades, fatores que contribuem para a ocorrência de eventos adversos (EAs). Recomenda-se a aplicação do checklist de cirurgia segura em todos os procedimentos cirúrgicos, minimizando assim o risco de EAs. ${ }^{(1-3)}$

Estudos demonstraram que a adesão ao checklist de cirurgia segura pode reduzir em até $60 \%$ as complicaçôes pós-cirúrgicas e em até $50 \%$ a taxa de mortalidade. ${ }^{(2,4-6)}$ Deste modo, o checklist, quando adaptado à instituição, bem como ao procedimento cirúrgico, constitui elemento essencial para a promoção da segurança, especialmente em cirurgias de grande porte. ${ }^{(7,8)}$

Neste cenário, o transplante hepático (THx) é considerado uma cirurgia de grande complexidade da atualidade ao considerarmos o tempo cirúrgico, presença da fase anepática e fatores relacionados ao enxerto. Assim, compreende-se que este procedimento apresenta consideráveis riscos, visto que o fígado é órgão vital do organismo responsável pela manutenção da estabilidade hemodinâmica, em especial, quanto à coagulação sanguínea e secreção de albumina. Esse procedimento consiste na retirada total do fígado doente, e consequentemente, a reco- locação de um fígado saudável, com a reconstrução anatômica vascular hepática e do trato biliar o mais próximo do padrão fisiológico. ${ }^{(9,10)}$

Durante o transplante, além do tempo prolongado de transoperatório (seis a dez horas), podem ocorrer alteraçôes hemodinâmicas, principalmente na fase anepática. No momento da retirada do fígado para a inserção do órgão saudável, há risco aumentado de sangramento devido aos fatores de coagulação, distúrbios hidroeletrolíticos relacionados e no equilíbrio ácido-base, o que torna estes pacientes mais vulneráveis a complicações. ${ }^{(10,11)}$

Assim, é necessário o gerenciamento constante no período perioperatório, viabilizando segurança e efetividade frente às peculiaridades do transplante, ao consideramos que a segurança cirúrgica está diretamente relacionada à complexidade do paciente e procedimento. Além disso, vale salientar que as equipes de saúde cirúrgicas ainda estão pouco orientadas ou até mesmo estruturadas para promover o trabalho em equipe, no sentido de minimizar os riscos e assim, promover cirurgias seguras. ${ }^{(1,2)}$ A Agência Nacional de Vigilância (ANVISA) por meio da biovigilância propóem monitoramento desde a seleção do doador, extração, preparação, conservação, controle, distribuição e implante dos órgãos. ${ }^{(12)}$

Ainda assim, apesar do progresso nos tratamentos, técnicas e segurança cirúrgica, cerca de 50\% dos EAs que poderiam ser evitados, continuam ocorrendo. Deve-se considerar a realidade mundial em que a taxa de EAs perioperatórios é 3\% e com taxa de mortalidade de $0,5 \%$. E ainda, que cerca de $7 \mathrm{mi}-$ lhóes de pacientes sofrem complicaçóes significativas ao ano, e um milhão de pessoas morrem durante ou imediatamente após a realização de cirurgias. ${ }^{(1,2)}$

Neste sentido, a busca de evidências na literatura nacional e internacional pode subsidiar a elaboração de um checklist de cirurgia segura, direcionado ao transplante hepático, proporcionando maior segurança à equipe de saúde na condução do procedimento, melhor qualidade nos cuidados e menor 
chance de EAs. Assim, o estudo propóe analisar evidências científicas que subsidiem práticas seguras no intraoperatório do transplante hepático.

Considerando que a OMS por meio do checklist estabelece três momentos envolvendo a segurança no ambiente cirúrgico: A primeira denominada "Sign in", a qual ocorrer antes da indução da anestesia, seguindo para "Time out" realizado imediatamente antes da incisão cirúrgica, e finalmente a "Sign out antes da saída do paciente da sala. ${ }^{(1,2)}$

Acredita-se que tais evidências identificadas na literatura possam subsidiar a adaptação do checklist para o THx nas três etapas propostas pela OMS, ao considerarmos que em diversas situações, pela gravidade do paciente e pela logística, muitos pacientes não foram avaliados pela equipe que está induzindo a anestesia e, ainda, pelo fato destes apresentarem alteraçôes hemodinâmicas frequentes devido a lesão hepática. Ainda, destaca-se a investigação da equipe nesta etapa quanto ao recebimento do enxerto, identificação e preparo no backtable e a necessidade de conferência dos dados do doador e receptor. Junto a isso, pontua-se que ao término do procedimento cirúrgico, o qual envolve a participação de vários profissionais, se faz necessário a checagem de questóes cirúrgicas, acessos, infusóes e drenos, entre outros, antes do transporte do paciente à unidade de terapia intensiva.

\section{Métodos}

Trata-se de revisão integrativa da literatura, realizada de janeiro a março de 2019, na Universidade Federal de Santa Catarina. O protocolo da revisão seguiu seis etapas: elaboração da questão de pesquisa; definição dos critérios para a busca na literatura; coleta dos dados; análise crítica do material obtido; avaliação e interpretação criteriosa das informaçôes obtidas; e apresentação dos resultados obtidos. ${ }^{(13)}$

Na primeira etapa, buscou-se definir de maneira clara o tema a ser investigado, para analisar o maior número possível de publicaçôes relacionados à segurança cirúrgica no transplante hepático. Assim, foi definida a questão norteadora: "Quais evidências na literatura científica subsidiam práticas seguras no intraoperatório transplante hepático?”.
Para o desenvolvimento dos critérios para a busca na literatura, foram consideradas bases de dados com abrangência de estudos relacionados a temática, sendo estas: Literatura Latino-Americana e do Caribe em Ciências da Saúde (LILACS), Biomedical Literature Citations and Abstracts (PUBMED), SCOPUS, Web of Science e Cumulative Indez to Nursing and Allied Health Literature (CINAHL) e na biblioteca Scientific Electronic Library Online (SciELO).

Para busca das publicações, foi utilizada uma combinação de descritores: "período intraoperatório", "centros cirúrgicos", "transplante de fígado", "gestão de segurança”, "segurança”, "segurança do paciente" e "lista de checagem", em português, inglês e espanhol, sem restrição de anos. Para a busca nas bases de dados foi utilizado a associação entre os operadores booleanos OR e AND desenvolvido com o apoio de uma bibliotecária para todas as bases, considerando como exemplo Scopus: "intraoperative period" OR "Intraoperative" OR "Transoperative" OR "surgicenters" OR "Surgicenters" OR "Surgicenter" OR "Surgical Center" OR "Surgical Centers" OR "Surgery Center" OR "Surgery Centers" AND "liver transplantation" OR "Liver Transplantation" OR "Liver Transplantations" OR "Hepatic Transplantation" OR "Hepatic Transplantations" OR "Liver Grafting” OR "liver transplant” OR “liver transplants" OR "hepatic transplant" OR "hepatic transplants" AND "patient safety" OR "safety" OR "safety management" OR checklist*.

Os critérios de inclusão dos estudos foram: estudos primários; relatos de experiência, protocolos e guidelines disponíveis nas bases de dados online; publicaçóes a qualquer tempo; nos idiomas português, inglês e espanhol; que abordem o transplante hepático com doador falecido. E os critérios de exclusão: cartas, editoriais, livros, resumos de anais de eventos, teses e dissertaçóes.

A busca nas bases foi realizada em janeiro de 2019, na sequência, submeteu-se o material obtido à ferramenta de gerenciamento bibliográfico, Mendeleyं, sendo excluídos os artigos duplicados. Posteriormente, dois pesquisadores, de maneira cegada, realizaram a leitura do título e resumo, excluindo os artigos que não estavam relacionados a 
temática proposta, considerando a questão norteadora, objetivo, critérios de inclusão e exclusão. Em seguida, os artigos foram lidos na íntegra, buscando identificar informaçóes que pudessem subsidiar a adaptação do checklist para o procedimento cirúrgico do THx.

Na sequência, realizada leitura na íntegra dos artigos e após o consenso entre os pesquisadores foi definido aos artigos que fariam parte da amostra, as informaçôes foram sintetizados com auxílio de roteiro. Em ambas as etapas foram considerados os critérios de inclusão e exclusão, questão norteadora e objetivo do estudo. As informaçôes necessárias para o estudo foram organizadas em uma planilha eletrônica com auxílio do software Excel versão 2013, onde foram registrados: título, ano de publicação, autores, periódico, base de dados, objetivos, tipo de estudo, nível de evidência, resultados e recomendaçóes. ${ }^{(13)}$

Durante a etapa de análise crítica do material obtido foi realizado um encontro com os pesquisadores, em que buscou-se avaliar as informaçóes obtidas nas publicaçôes incluídas, assim como, a classificação do nível de evidência dos estudos ${ }^{(14)}$ possíveis vieses, bem como os principais achados dos estudos.

A avaliação e interpretação criteriosa das informaçôes obtidas foi realizada com os pesquisadores e dois profissionais com expertise no tema, os quais foram definidos pelo tempo de atuação no $\mathrm{THx}$ em ambiente cirúrgico (superior a dez anos), sendo identificadas recomendaçóes mais importantes e com maior nível de evidência possível, as quais podem sugerir mudanças na prática.

O fluxograma referente ao processo de busca nas bases de dados será apresentado a seguir (Figura 1).

Foram identificadas 511 publicaçôes. Após leitura do título e resumo dos estudos, 278 foram excluídos, 252 estavam relacionados há estudos que abordavam, somente, a indicação do transplante, principais resultados relacionados ao transplante, sobrevida do enxerto e qualidade de vida; e os outros 26 manuscritos estavam relacionados a artigos de discussão, relato de experiência e editoriais. Foram lidos então, 27 manuscritos na íntegra e excluídos 11 artigos por não estarem relacionados a temática do intraoperatório. Finalmente, foram selecionados para a revisão 16 artigos.

Para apresentar as recomendações de segurança cirúrgica no intraoperatório do transplante hepático, as quais podem sugerir mudanças na prática, estas foram organizadas em quatro categorias considerando os achados mais relevantes: Cuidados relacionados a hipotermia; Recomendaçóes para extubação precoce; Transfusão de hemocomponentes e Protocolo anestésico.

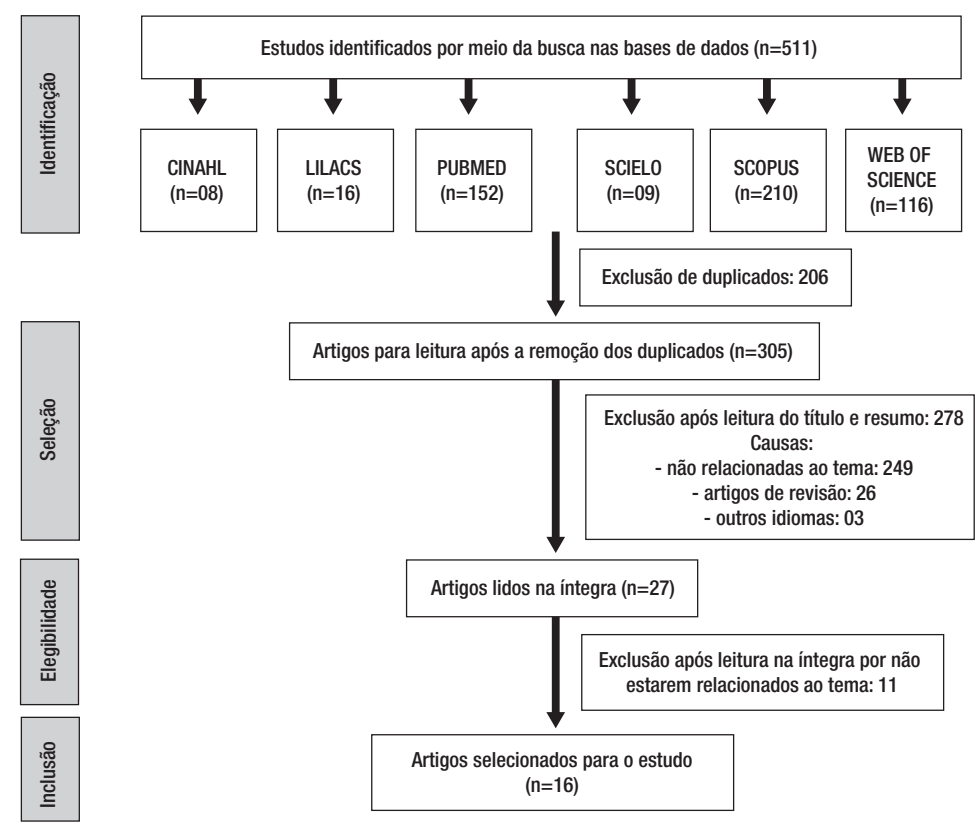

Figura 1. 0 fluxograma do processo de seleção dos estudos 


\section{Resultados}

As publicaçóes incluídas na revisão encontramse distribuídas, na maior parte, nas bases de dados SCOPUS (11; 68,75\%), seguida da Web of Science (3; 18,75\%). Os estudos foram publicados entre 1996 e 2018, no entanto, a maior parte das publicaçôes concentrou-se em 2010. Quanto ao nível de evidência, os estudos concentraram-se no Nível 4 (11; $68,75 \%$ ), sendo apenas um classificado com nível de evidência $2(6,25 \%)$. Os resultados são apresentados a seguir, contendo a referência, o método, o nível de evidência e os objetivos (Quadro 1).

A seguir, são apresentadas as recomendaçóes para a segurança cirúrgica no intraoperatório de transplante hepático, estruturada a partir das quatro categorias.

\section{Categoria 1 - Cuidados relacionados a hipotermia}

A categoria apresenta evidências para a prevenção da hipotermia durante o intraoperatório. As infor- maçóes obtidas apontam a necessidade de manter a temperatura do paciente próximo a $36^{\circ} \mathrm{C}$, em virtude que esta condição pode afetar a coagulação, função cardíaca, contribuir para o surgimento de arritmias cardíacas e infecçôes pós-operatórias, além do risco de parada cardiorrespiratória. ${ }^{(22,28,30)}$

As evidências encontradas nos estudos analisados apontam que no período intraoperatório, a temperatura corporal deve ser continuamente monitorizada, utilizando-se dispositivos que verifiquem a temperatura central por meio de cateter na artéria pulmonar, mediante leitura da sonda esofágica ou cateter urinário. $^{(22,28,30)}$

\section{Categoria 2 - Recomendações para extubação precoce}

Nesta categoria, são apontadas as evidências para a realização da extubação precoce, demonstrando que a ventilação mecânica após o transplante hepático já não se justifica, sendo a extubação precoce em

Quadro 1. Síntese dos artigos incluídos no estudo

\begin{tabular}{|c|c|c|c|}
\hline Referência & Método / Nível de evidência & Objetivos & $\begin{array}{l}\text { Estudos relacionados } \\
\text { com as categorias }\end{array}$ \\
\hline Houben et al (2018) $)^{(15)}$ & $\begin{array}{l}\text { Protocolo de estudo randomizado } \\
\text { Nível de evidência } 7\end{array}$ & $\begin{array}{l}\text { Apresentar um protocolo de estudo randomizado utilizando o dispositivo de vedação } \\
\left(\text { LigaSure }{ }^{\top M} \text { ) e um dissector de ultrassom (HARMONIC ACE } ®+7\right) \text { durante } 0 \text { intraoperatório. }\end{array}$ & Categoria 3 \\
\hline Nascimento et al. $(2018)^{(16)}$ & $\begin{array}{l}\text { Relato de caso } \\
\text { Nível de evidência } 7\end{array}$ & $\begin{array}{l}\text { Descrever o caso de um paciente cirrótico em uso de varfarina, cujo manejo da coagulação } \\
\text { durante o transplante hepático foi guiado por tromboelastometria. }\end{array}$ & Categoria 3 \\
\hline Akbulut et al. $(2013)^{(17)}$ & $\begin{array}{l}\text { Estudo de corte/caso controle } \\
\text { Nível de evidência } 4\end{array}$ & $\begin{array}{l}\text { Investigar a eficácia terapêutica e segurança do sistema de autotransfusão contínua durante } \\
\text { o transplante hepático de pacientes com carcinoma hepatocelular. }\end{array}$ & Categoria 3 \\
\hline $\begin{array}{l}\text { Schumann, Mandell, } \\
\text { Marcaldo (2013) }\end{array}$ & $\begin{array}{l}\text { Estudo quantitativo, descritivo } \\
\text { Nível de evidência } 4\end{array}$ & $\begin{array}{l}\text { Descrever os cuidados intraoperatórios e o papel do anestesiologista no manejo } \\
\text { intraoperatório do transplante hepático. }\end{array}$ & Categoria 4 \\
\hline Biancofiore, Rocca (2012) ${ }^{(19)}$ & $\begin{array}{l}\text { Estudo quantitativo, descritivo } \\
\text { Nível de evidência } 4\end{array}$ & $\begin{array}{l}\text { Investigar como se desenvolve a abordagem intra e pós-operatória para pacientes } \\
\text { submetidos ao transplante de fígado ortotópico. }\end{array}$ & Categoria 2 e Categoria 4 \\
\hline Feng et al. (2010)(20) & $\begin{array}{l}\text { Estudo clínico randomizado } \\
\text { Nível de evidência } 2\end{array}$ & $\begin{array}{l}\text { Avaliar o uso da técnica de baixa pressão venosa central visando maior segurança no } \\
\text { transplante hepático. }\end{array}$ & Categoria 3 e Categoria 4 \\
\hline Skurzak et al. (2010)(21) & $\begin{array}{l}\text { Estudo quantitativo de coorte } \\
\text { Nível de evidência } 4\end{array}$ & $\begin{array}{l}\text { Fornecer uma regra de extubação simples para desmame acelerado na sala de cirurgia, } \\
\text { através de pontuação simples operacional segura após o transplante hepático. }\end{array}$ & Categoria 2 \\
\hline Rocca et al. $(2010)^{(22)}$ & $\begin{array}{l}\text { Estudo de relato de experiência } \\
\text { Nível de evidência } 5\end{array}$ & Apresentar política de prevenção para detectar erros precocemente no transplante hepático. & $\begin{array}{l}\text { Categoria 1, Categoria } 3 \text { e } \\
\text { Categoria } 4\end{array}$ \\
\hline Glanemann et al. $(2007)^{(23)}$ & $\begin{array}{l}\text { Estudo quantitativo, retrospectivo } \\
\text { Nível de evidência } 4\end{array}$ & $\begin{array}{l}\text { Identificar se a extubação precoce em sala de cirurgia aumenta a sobrevida e segurança do } \\
\text { paciente. }\end{array}$ & Categoria 2 e Categoria 3 \\
\hline Massicotte et al. (2008) & $\begin{array}{l}\text { Estudo prospectivo, comparativo não } \\
\text { experimental } \\
\text { Nível de evidência } 4\end{array}$ & $\begin{array}{l}\text { Avaliar se os anestesiologistas poderiam reduzir os requisitos de transfusão de concentrado } \\
\text { de hemácias no intraoperatório durante o transplante hepático, eliminando a transfusão de } \\
\text { plasma. }\end{array}$ & Categoria 3 \\
\hline Mandell et al. (2002)(25) & $\begin{array}{l}\text { Estudo de corte } \\
\text { Nível de evidência } 4\end{array}$ & $\begin{array}{l}\text { Avaliar quais características dos pacientes receptores de transplante de fígado não } \\
\text { selecionados resultariam em sucesso ou falha de extubação pós-operatória imediata. }\end{array}$ & Categoria 2 \\
\hline Schroeder et al. (2004) $)^{(26)}$ & $\begin{array}{l}\text { Estudo quantitativo, retrospectivo } \\
\text { Nível de evidência } 4\end{array}$ & $\begin{array}{l}\text { Avaliar a segurança clínica de estratégia de manejo de fluídos de baixa pressão venosa } \\
\text { central em pacientes submetidos a transplante hepático. }\end{array}$ & Categoria 3 \\
\hline Viana et al. (1999) ${ }^{(27)}$ & $\begin{array}{l}\text { Estudo quase experimental } \\
\text { Nível de evidência } 3\end{array}$ & $\begin{array}{l}\text { Avaliar a experiência da Unidade de Transplante de Fígado do Hospital Universitário de } \\
\text { Coimbra quanto aos aspectos circulatórios intraoperatórios realizados em pacientes com } \\
\text { polineuropatia amiloidótica familiar. }\end{array}$ & Categoria 2 e Categoria 4 \\
\hline Neelakanta et al. (1998) ${ }^{(28)}$ & $\begin{array}{l}\text { Estudo quantitativo, retrospectivo } \\
\text { Nível de evidência } 4\end{array}$ & $\begin{array}{l}\text { Revisar experiência com permutadores de calor durante o transplante hepático ortotópico e } \\
\text { investigar os efeitos da normotermia na perda de sangue durante o período neo-hepático e } \\
\text { na estabilidade cardíaca durante a reperfusão do fígado doado. }\end{array}$ & Categoria 1 \\
\hline Neelakanta et al. $(1997)^{(29)}$ & $\begin{array}{l}\text { Estudo quantitativo, retrospectivo } \\
\text { Nível de evidência } 4\end{array}$ & $\begin{array}{l}\text { Avaliar o valor e segurança da extubação traqueal na sala cirúrgica no final do transplante } \\
\text { hepático. }\end{array}$ & Categoria 2 \\
\hline Russell, Freeman $(1996)^{(30)}$ & $\begin{array}{l}\text { Estudo quantitativo, prospectivo } \\
\text { Nível de evidência } 4\end{array}$ & $\begin{array}{l}\text { Comparar as temperaturas da bexiga, esôfago e artéria pulmonar em um grupo de pacientes } \\
\text { submetidos a transplante hepático. }\end{array}$ & Categoria 1 \\
\hline
\end{tabular}


sala de cirurgia viável, segura e bem tolerada pela maioria dos pacientes. ${ }^{(21-23,25,27)}$

A extubação precoce, seguida de respiração expontânea, melhora a drenagem venosa e a circulaçáo do enxerto doado, contribuindo assim, para a recuperação precoce do enxerto hepático, pois evita qualquer diminuição potencial do fluxo sanguíneo hepático, proprociona maior conforto ao paciente e facilita a mobilização precoce. A maioria dos pacientes não apresentam necessidade de reintubação traqueal na UTI. ${ }^{(23,29)}$

\section{Categoria 3 - Transfusão de hemocomponentes}

Por meio dessa categoria são apresentadas as evidências para minimizar a utilização de componentes sanguíneos, uma vez que produtos sanguíneos aumentam a chance de morbidade ou mortalidade, além de aumentar as chances de desenvolvimento de anticorpos, o que propicia maior risco de rejeição. ${ }^{(24)}$

Os cuidados para minimizar o uso dos componentes envolvem a realização de exames frequentes, análise dos gases sanguíneos, bioquímica, contagem de concentrado de hemácias, tromboelastograma e monitorização rigorosa da coagulação, transfusão autóloga de glóbulos vermelhos, através do uso de sistemas como de autotransfusão contínua ou cell Saver. Como forma de monitorar a congulação, sugere-se avaliar o tempo de tromboplastina parcial ativa e plaquetas. Pode-se utilizar, ainda, a ecocardiografia transesofágica. Ainda na pespectiva de melhora do sangramento no intraoperatório, o uso de varfarina se mostrou efetivo, visto que o paciente não recebeu transfusão de sangue até o fim do transplante. Em um protocolo de pesquisa a ser utilizado o dispositivo de vedação $\left(\right.$ LigaSure $^{\mathrm{TM}}$ ) e um dissector de ultrassom (HARMONIC $\mathrm{ACE}^{\oplus}+7$ ) durante o intraoperatório, as hipóteses consideram a possibilidade de redução em $80 \%$ do sangramento no intraoperatório. ${ }^{(15-17,22-24)}$

Ainda como forma de realizar autotransfusão, os anestesistas podem utilizar técnicas como de baixa pressão venosa central durante o transplante, não sendo recomendado para pessoas com doença hepática terminal e função hipovolêmica potencialmente comprometida. ${ }^{(20,26)}$

\section{Categoria 4 - Protocolo anestésico}

As evidências apontam a necessidade de utilização de protocolos de anestesia, os quais visam minimizar e prevenir EAs e o seu adequado manejo durante o transplante hepático. Os achados indicam a necessidade de adoção de padrôes anestésicos com protocolos institucionais, aumentando assim a segurança do paciente. ${ }^{(18,20,22)} \mathrm{O}$ manejo anestésico no transplante hepático deve basear-se em um sistema adequado de monitoramento de sinais vitais e na administração de fármacos, devido aos efeitos sistêmicos nos pacientes, devendo ser bem conhecidos na prática anestésica, além do gerenciamento de risco anestésico. ${ }^{(22,27)}$

\section{Discussão}

A revisão permitiu identificar apenas um estudo com alto nível de evidência (Nível 2). Vale salientar que a produção de conhecimento científico é a base para mudanças na prática, além de ser indispensável na assistência, possibilitando autonomia para as equipes, embasamento da prática clínica e segurança no processo de trabalho. ${ }^{(31,32)}$

$\mathrm{O}$ número de estudos voltados à segurança do paciente no centro cirúrgico ainda é sutil. Salientase a necessidade de produção de estudos com delineamentos de pesquisas com evidências fortes (ensaios clínicos randomizados controlados e estudos de coorte). ${ }^{(11)}$ Nos estudos identificados não há evidências que possam apoiar a adaptação checklist para o THx nas três etapas propostas pela OMS, visto que não foi identificado informações que possam guiar a equipe para rastrear dados relacionados ao ao clampeamento da aorta, tempo de isquemia, condiçóes da perfusão do órgão, recebimento do enxerto na sala cirúrgica, identificação e preparo no backtable, tempo de isquemia quente e reperfusão do órgão. Ainda, não há informações que possam auxiliar a equipe na conferência de dados do doador e do receptor. Tais informações são fundamentais e essenciais para prevenir agravos/eventos adversos e promover qualidade e segurança na assistência desenvolvida ao paciente submetido ao THx.

No sentido de perpetuar a segurança dos transplantes no Brasil, a ANVISA propóem estratégias 
de monitoramento desde a seleção do doador, extração, preparação, conservação, controle e distribuição do órgão, tecido ou células até a sua utilização pelo receptor. A proposta desta instituição é rastrear e mapear, além de identificar dados relacionados a possíveis eventos adversos, propondo que profissionais envolvidos no processo de doação e transplante identifiquem quais situaçóes possam indicar dano ao processo. ${ }^{(12)}$ Assim, compreende-se que apesar da maioria dos estudos apresentar nível de evidência IV, foi possível identificar informaçóes relevantes quanto à prevenção de complicaçóes e eventos adversos no desenvolvimento seguro da cirurgia do transplante hepático. Tais achados podem promover mudanças significativas na segurança do paciente no intraoperatório.

As evidências relacionadas a prevenção da hipotermia intraoperatória, bem como, para cirurgias de grande porte são destacadas nos estudos, que apontam a importância de manter a temperatura corporal acima de $36^{\circ} \mathrm{C}$, prevenindo riscos ao paciente, que pode evoluir para arritmias e até mesmo a morte. ${ }^{(22,28,30)}$ As evidências pontuam cuidados factíveis de serem desenvolvidos pela equipe, promovendo medidas preventivas, passivas e ativas, de aquecimento do paciente, contribuindo também para a prevenção de complicações. ${ }^{(33)}$

Outra evidência direcionada à cirurgia segura e risco de complicações envolve a extubação precoce. Estudos apontam a importância desta conduta no sentido de minimizar o risco de infecçóes, em virtude da baixa imunidade manifestada pelo receptor do transplante hepático. ${ }^{(23,25,34)}$ Ainda indicam a baixa adesão da equipe anéstesica, por não existirem protocolos ou guias institucionais. Reforça-se a importância da segurança, baseada em ações efetivas, que subsidiem a equipe em todas atividades, para proteção do paciente submetido a procedimentos invasivos e complexos. ${ }^{(31,35)}$

No que se refere ao intraoperatório, as evidências apontam a importância da redução do uso de hemocomponentes. Os estudos reinteram a necessidade de avaliação cautelosa para produtos oriundos do sangue. ${ }^{(18,22,24)}$ A hemotransfusão pode acarretar sérios riscos ao paciente, tais como infecçôes, reação febril não hemolítica, lesão pulmonar, hipocalcemia, hemólise não imune, reação alérgica, hemólise, hipotermia, entre outros. Logo, devem ser utilizadas estratégias que minimizem o risco de sangramento, além de protocolos atualizados que possam uniformizar as condutas e minizar EAs. ${ }^{36,37)}$ Evidências mostram a importância de cuidados direcionados a minimizar o risco de sangramento, como o uso de medicamentos, equipamentos e instrumentos, ferramentas de apoio para o cuidado intraoperatório. ${ }^{(15,16)}$

O desenvolvimento da anestesia no transplante hépatico utilizando guias de boas práticas foram evidências apontadas nos estudos. ${ }^{(18,19,22,27)}$ Sua utilização traz maior segurança para a equipe e pacientes, e consequentemente, maior qualidade na indução anestésica para o procedimento cirúrgico. Seu uso pode diminuir os riscos aos pacientes, auxiliando na tomada de desisão sob a demanda apresentada pelo paciente. ${ }^{(35,38)}$

Neste sentido, pondera-se que as informaçóes identificadas no estudo podem subsidiar a construção de um checklist adaptado ao intraoperatório do transplante hepático. O enfermeiro por ser o profissional que gerencia e coordena o ambiente cirúrgico desde a chegada do paciente na sala, indução anestésica, recebimento do órgãos, acompanhamento do backtable, conferência entre dados do receptor e doador, entre outros, até a transferência do receptor a unidade de terapia intensiva. ${ }^{(39)}$

Frente as evidências obtidas, é possível que o enfermiro do bloco operatório insira em seu dia a dia, açóes de controle e monitoramento da hipotermia, anestesia e hemoderivados registrando efeitos não desejados ou inesperados que possam surgir no intraoperatório. Ao mesmo tempo em que poderá aderir, por meio de intervençôes de enfermagem, cuidados relacionados as evidências apresentadas minimizando riscos associados a tais situaçôes e potencializando a segurança no intraoperatório do THx. A segurança nas cirurgias de grande porte surge como responsabilidade, compromisso ético, moral e de qualidade à equipe do ambiente cirúrgico, visto que muitos pacientes podem chegar ao centro cirúrgico em condiçóes graves de saúde, em especial no $\mathrm{THx}^{(1,10,25)}$

Como limitaçóes apontamos a escassez de informaçôes que possam proporcionar açóes direciona- 
dos ao monitoramento do intraoperatório do THx. Sob o ponto de vista metodológico, limitaçóes da estratégia de busca e das bases de dados selecionadas, podem ter contribuído para o número reduzido de publicações nessa temática, além de não identificarmos estudos com níveis de evidências fortes (estudos randomizados duplo cego, estudo com pré e pós teste, estudo de corte entre outros.

\section{Conclusão}

As evidências identificadas para subsidiar, futuramente, a elaboração de um checklist de cirurgia segura direcionado a este procedimento, destacando-se: a prevenção da hipotermia; importância do planejamento da extubação precoce; definição de critérios para uso de hemocomponentes; e a importância do desenvolvimento e adoção de protocolos e guias para o ato anestésico. Considerando os achados desse estudo, recomenda-se o desenvolvimento de outros estudos nesta temática. Junto a isso, aponta-se a necessidade de novos estudos que possam investigar a prevenção de eventos adversos no intraoperatório relacionados à manutenção temperatura corporal, ao posicionamento cirúrgico, à transfusão de hemoderivados, à reperfusão do órgão, entre outras temáticas que favoreçam a prática segura nesta cirurgia.

\section{Referências}

1. Agência Nacional de Vigilância Sanitária (ANVISA). Assistência Segura: Uma Reflexão Teórica Aplicada à Prática [Internet]. Brasília (DF): ANVISA; 2017 [citado 2019 Mai 31]. Disponível em:https://www20.anvisa. gov.br/segurancadopaciente/index.php/publicacoes/item/caderno-1assistencia-segura-uma-reflexao-teorica-aplicada-a-pratica

2. Agência Nacional de Vigilância Sanitária (ANVISA). Cirurgias Seguras Salvam Vidas [Internet]. Brasília (DF); ANVISA; 2015 [citado 2019 Mai 31]. Disponível em: http://www20.anvisa.gov.br/segurancadopaciente/ index.php/noticias/60-cirurgias-seguras-salvam-vidas [PortuguêsBrasil]

3. Grazziano ES. Safety in surgery care: where are we? Revista SOBECC. 2015;20(2):5-11.

4. Yamanaka NM, Malta F, Cabanas A. Nursing audit: the Security Surgical from deployment to monitoring. Rev Eletr Enferm Vale do Paraíba. 2013;1(4):1-15.

5. Ribeiro HC, Quites HF, Bredes AC, Sousa KA, Alves M. [Adherence to completion of the safe surgery checklist]. Cad Saude Publica. 2017;33(10):e00046216.
6. Negreiros FD, Pequeno AM, Garcia JH, Aguiar MI, Moreira TR, Flor MJ. Multi-professional team's perception of nurses' competences in liver transplantations. Rev Bras Enferm. 2017;70(2):242-8.

7. Henriques $A H$, Costa SS, Lacerda JS. Nursing care in surgical patient safety: an integrative review. Cogitare Enferm. 2016;21(4):1-9.

8. Cruz IA, Selow ML. Avaliar a relevância do protocolo de cirurgia segurança nas instituições de saúde. Rev Dom Acadêmico. 2017;2(1):188-96.

9. Ribeiro MA Jr, Medrado MB, Rosa OM, Silva AJ, Fontana MP, CruvinelNeto J, et al. Liver transplantation after severe hepatic trauma: current indications and results. Arq Bras Cåir Dig. 2015;28(4):286-9.

10. Mendes KD, Lopes NL, Fabris MA, Castro-e-Silva OJ, Galvão CM. Sociodemographic and clinical characteristics of candidates for liver transplantation. Acta Paul Enferm. 2016;29(2):128-35.

11. Araujo MP, Oliveira AC. What changes may occur in surgical care after the implemenntation of patient safety centers? Rev Enferm Centro Oeste Mineiro. 2015;5(1):1542-51.

12. Agência Nacional de Vigilância Sanitária (ANVISA). Guia de Biovigilância de Células, Tecidos e Órgãos \& Manual de Notificação [Internet]. Brasília (DF): ANVISA; 2016 [citado 2019 Mai 31]. Disponível em: $\quad$ http://portal.anvisa.gov.br/documents/33868/3055469/ Guia+de+Biovigil\%C3\%A2ncia+de+C\%C3\%A9lulas $\% 2 C+$ Tecidos +e+\%C3\%93rg\%C3\%A30s+\%26+Manual+de+Notifica\%C3\%A7\% C3\%A3o/bfe1f75d-4351-4ca9-b56d-54c985213154

13. Ganong LH. Integrative reviews of nursing research. Res Nurs Health. 1987;10(1):1-11.

14. Melnyk BM, Fineout-Overholt E. Making the case for evidence-based practice. Evidence-based practice in nursing \& healthcare. A guide to best practice. United States: Wolters Kluwer; 2011. p. 3-24.

15. Houben P, Khajeh E, Hinz U, Knebel P, Diener MK, Mehrabi A. SEALIVE: the use of technical vessel-sealing devices for recipient hepatectomy in liver transplantation: study protocol for a randomized controlled trial. Trials. 2018;19(1):380.

16. Nascimento JC, Marinho DS, Escalante RD, Pereira Junior BE, Lopes CG, Nunes RR. [Monitoring of coagulation by intraoperative thromboelastometry of liver transplantation in a patient using warfarin - case report]. Rev Bras Anestesiol. 2018;68(6):645-9.

17. Akbulut S, Kayaalp C, Yilmaz M, Ince V, Ozgor D, Karabulut K, et al. Effect of autotransfusion system on tumor recurrence and survival in hepatocellular carcinoma patients. World J Gastroenterol. 2013;19(10):1625-31.

18. Schumann R, Mandell MS, Mercaldo N, Michaels D, Robertson A, Banerjee A, et al. Anesthesia for liver transplantation in United States academic centers: intraoperative practice. J Clin Anesth. 2013;25(7):542-50.

19. Biancofiore G, Della Rocca G; SIAARTI Study Group on organs donation and abdominal organs transplantation. Perioperative management in orthotopic liver transplantation: results of an Italian national survey. Minerva Anestesiol. 2012;78(6):668-74.

20. Feng $Z Y, X u X$, Zhu SM, Bein B, Zheng SS. Effects of low central venous pressure during preanhepatic phase on blood loss and liver and renal function in liver transplantation. World J Surg. 2010;34(8):1864-73.

21. Skurzak S, Stratta C, Schellino MM, Fop F, Andruetto P, Gallo M, et al. Extubation score in the operating room after liver transplantation. Acta Anaesthesiol Scand. 2010;54(8):970-8.

22. Della Rocca G, De Flaviis A, Costa MG, Chiarandini P, Pompei L, Venettoni S. Liver transplant quality and safety plan in anesthesia and intensive care medicine. Transplant Proc. 2010;42(6):2229-32. 
23. Glanemann M, Hoffmeister R, Neumann U, Spinelli A, Langrehr JM, Kaisers $\mathrm{U}$, et al. Fast tracking in liver transplantation: which patient benefits from this approach? Transplant Proc. 2007;39(2):535-6.

24. Massicotte L, Beaulieu D, Thibeault L, Roy JD, Marleau D, Lapointe R, et al. Coagulation defects do not predict blood product requirements during liver transplantation. Transplantation. 2008;85(7):956-62.

25. Mandell MS, Lezotte D, Kam I, Zamudio S. Reduced use of intensive care after liver transplantation: patient attributes that determine early transfer to surgical wards. Liver Transpl. 2002;8(8):682-7.

26. Schroeder RA, Collins BH, Tuttle-Newhall E, Robertson K, Plotkin J, Johnson LB, et al. Intraoperative fluid management during orthotopic liver transplantation. J Cardiothorac Vasc Anesth. 2004;18(4):438-41.

27. Viana JS, Bento C, Vieira H, Neves S, Seco C, Elvas L, et al. Heamodynamics during liver transplantation in familial amtloidotic polyneuropathy: study of the instraoperative cardiocirculatory. Rev Port Cardiol. 1999;18(8):689-97.

28. Neelakanta G, Colquhoun S, Csete M, Koroleff D, Mahajan A, Busuttil RW. Efficacy and safety of heat exchanger added to venovenous bypass circuit during orthotopic liver transplantation. Liver Transpl Surg. 1998;4(6):506-9.

29. Neelakanta G, Sopher M, Chan S, Pregler J, Steadman R, Braunfeld M, et al. Early tracheal extubation after liver transplantation. J Cardiothorac Vasc Anesth. 1997;11(2):165-7.

30. Russell SH, Freeman JW. Comparison of bladder, oesophageal and pulmonary artery temperatures in major abdominal surgery. Anaesthesia. 1996;51(4):338-40.
31. Lourenção DC, Tronchin DM. Patient safety in the surgical environment: translation and cross-cultural adaptation of validated instrument. Acta Paul Enferm. 2016;29(1):1-8.

32. Campos JA, Costa AC, Dessotte CA, Silveira RC. Scientifc Production in Perioperative Nursing from 2003 to 2013. Rev SOBECC. 2015;20(2):81-95.

33. Danczuk RFT, Nascimento ERP, Silveira NR, Hermida PMV, Raísa MA. Heating methods in the prevention of intraoperative hypothermia of elective abdominal surgery. Esc Anna Nery. 2015;19(4):578-84.

34. Paredes ER, Navilli V Junior, Oliveira AC. Protocol for the prevention extubation failure as a strategy to avoid complications of early reintubation. Rev UNILUS Ensino Pesqui. 2013;10(19):1-19.

35. Zanetti ML. Advanced nursing practice: strategies for training and knowledge building. Rev Lat Am Enfermagem. 2015;23(5):779-80.

36. Soares JM, Queiroz AG, Queiroz VK, Falbo AR, Silva MN, Couceiro TC, et al. Anesthesiologists' knowledge about packed red blood cells transfusion in surgical patients. Rev Bras Anestesiol. 2017;67(6):58491.

37. Santana HT, Siqueira HN, Costa MM, Oliveira DC, Gomes SM, Sousa FC, et al. Surgical patient safety from the perspective of health surveillance — a theoretical reflection. Vig Sanit Debate. 2014;2(2):34-42.

38. Nunes DA. Segurança do paciente cirúrgico em Rondônia: uma análise crítica sobre o processo de trabalho. Saber Científico. 2017;6(1):70-5.

39. Amorin JS, Brito AM, Silva FF, Assunção JM, Pimenta JL, Resende MK. Intraoperatory of liver transplantation: evidence based nursing pratic. Rev SOBECC. 2011;16(1):40-7. 